\title{
SIGNIFICADO DE VIDA NO TRÂNSITO: REPRESENTAÇÕES SOCIAIS DEMEMBROS DA REDE VIDA NO TRÂNSITO
}

Mirela Schmidt Virgilio ${ }^{1}$

Eliane Regina Pereira do Nascimento²

Patricia Madalena Vieira Hermida 2

Maria Itayra Coelho de Souza Padilha ${ }^{2}$

Keyla Cristine do Nascimento ${ }^{2}$

José Luis Guedes dos Santos ${ }^{2}$

\author{
http://orcid.org/0000-0001-5101-8938 \\ http://orcid.org/0000-0001-6372-9059 \\ http://orcid.org/0000-0002-7969-357X \\ http://orcid.org/0000-0001-9695-640X \\ http://orcid.org/0000-0003-4157-2809 \\ http://orcid.org/0000-0003-3186-8286
}

Objetivo: compreender o significado de vida no trânsito na perspectiva de membros da Rede Vida no Trânsito. Metodologia: estudo exploratório descritivo, qualitativo, orientado pelo referencial teórico das representações sociais. A coleta de dados ocorreu de junho a agosto de 2016 , por meio de entrevistas com 30 participantes. Utilizou-se a técnica do discurso do sujeito coletivo para análise de dados. Resultados: emergiram dos dados representações retratadas na Ancoragem (promoção de vida no trânsito) e na Ideia Central (preservação da vida pela redução dos acidentes). A promoção da vida no trânsito é representada por educação; respeito; tolerância; investimento e segurança. A preservação da vida refere-se à diminuição de óbitos no trânsito e transporte com segurança. Conclusão: a vida no trânsito representa condições ideais de trânsito e mobilidade com segurança. Porém, a realidade cotidiana sinaliza a necessidade de melhorias a fim de garantir vida no trânsito com segurança.

Descritores: Acidentes de Trânsito; Política Pública; Colaboração Intersetorial; Segurança; Enfermagem em Emergência.

\section{MEANING OF LIFE IN TRAFFIC: SOCIAL REPRESENTATIONS OF MEMBERS OF THE TRAFFIC LIFE NETWORK}

Objective: to understand the meaning of life in traffic from the perspective of members of the Life in Traffic Network. Method: a descriptive, qualitative exploratory study, guided by the theoretical framework of social representations. Data collection took place from June to August 2016 , through interviews with 30 participants. The collective subject discourse technique was used for data analysis. Results: emerged from the data representations portrayed in Anchorage (life promotion in traffic) and Central Idea (preservation of life by reducing accidents). The promotion of life in traffic is represented by education; respect; tolerance; investment and security. The preservation of life refers to the reduction of deaths in traffic and transport safely. Conclusion: life in traffic represents ideal traffic conditions and safe mobility. However, everyday reality signals the need for improvements to ensure life in traffic safely. Descriptors: Traffic Accidents; Public Policy; Intersectoral Collaboration; Safety; Emergency Nursing.

\section{SIGNIFICADO DE LA VIDA EN EL TRÁFICO: REPRESENTACIONES SOCIALES DE LOS MIEMBROS DE LA RED DE VIDA DEL TRÁFICO}

Objetivo: comprender el significado de la vida en el tráfico desde la perspectiva de los miembros de la Red de Vida en el Tráfico. Método: estudio exploratorio descriptivo, cualitativo, guiado por el marco teórico de las representaciones sociales. La recopilación de datos tuvo lugar de junio a agosto de 2016, a través de entrevistas con 30 participantes. La técnica del discurso del sujeto colectivo se utilizó para el análisis de datos. Resultados: surgieron de las representaciones de datos retratadas en Anclaje (promoción de la vida en el tráfico) e Idea central (preservación de la vida mediante la reducción de accidentes). La promoción de la vida en el tráfico está representada por la educación; respeto tolerancia inversión y seguridad. La preservación de la vida se refiere a la reducción de muertes en el tráfico y el transporte de manera segura. Conclusión: la vida en el tráfico representa condiciones ideales de tráfico y movilidad segura. Sin embargo, la realidad cotidiana señala la necesidad de mejoras para garantizar la vida en el tráfico de manera segura.

Descriptores: Accidentes de Tránsito; Política Pública; Colaboración Intersectorial; Seguridad; Enfermeria de Urgencia.

${ }^{1}$ Hospital Regional Dr Homero de Miranda Gomes de Santa Catarina, SC, Brasil.

'Universidade Federal de Santa Catarina, SC, Brasil.

Autor Correspondente: José Luis Guedes dos Santos: joseenfermagem@gmail.com

Recebido: 09/04/2020 - Aceito: 28/10/2020 


\section{INTRODUÇÃo}

Os acidentes de trânsito estão entre as principais causas de morte e traumas em todo o mundo, sendo que as lesões e sequelas por este agravo impõem um pesado ônus às nações, impactando serviços de segurança, de infraestrutura, de seguridade social e de saúde e na qualidade de vida ${ }^{1}$. No Brasil, as lesões por acidentes no trânsito ocupam a segunda causa de morte entre todos os óbitos por motivos externos ${ }^{2}$ sendo o país convidado a participar do projeto Road Safety in Ten Countries (RS 10), que tem como objetivo promover intervenções efetivas de segurança no trânsito com redução de mortes e ferimentos graves, tornando o período de 2011-2020 a década de ações para a segurança no trânsito ${ }^{3}$.

No Brasil, o Projeto iniciou em 2010 com o Programa Vida no Trânsito (PVT), coordenado pelo Ministério da Saúde com a cooperação técnica da Organização Pan-Americana da Saúde (OPAS), cujas diretrizes consistem no planejamento participativo, na descentralização administrativa e na intersetorialidade. Foi implantando inicialmente em cinco capitais brasileiras, uma em cada região do país (Palmas, Teresina, Belo Horizonte, Curitiba, e Campo Grande), escolhidas de acordo com critérios como a taxa de mortalidade por acidente de trânsito, capacidade de intervenção e adesão dos prefeitos. A partir de 2012, o PVT expandiu-se para as demais metrópoles ${ }^{4}$.

O desempenho do PVT se revelou positivo na maioria das capitais, com destaque para as intervenções intersetoriais pautadas na parceria entre os setores de Trânsito, Segurança Pública e Saúde 5 . Para fortalecer o PVT, foi criada em Florianópolis, em julho de 2014, a Rede Vida no Trânsito (RVT), que reúne organizações governamentais, sociais e empresariais, aberta à participação de indivíduos ou organizações. A Rede tem como missão garantir o Direito à Vida no Trânsito. Para isso, definiu como visão fazer de Florianópolis, até 2020 , capital referência em educação, respeito, gentileza e paz no trânsito, reduzindo o número de mortes e feridos graves ${ }^{1}$.

Uma vez que os estudos sobre os acidentes de trânsito destacam principalmente aspectos clínicos e epidemiológicos $^{6-12}$, realizou-se este estudo sobre os significados de vida no trânsito entre membros da Rede Vida no Trânsito visando à ampliação da abordagem do tema. Assim, recorre-se às representações sociais como suporte teórico deste estudo, no intuito de compreender as razões sociológicas de quem almeja conquistar mudanças no trânsito. A Representação Social é o reflexo das relações complexas, reais e imaginárias, objetivas e simbólicas que o sujeito mantém com o objeto ou tema. Essas relações fazem da representação um sistema organizado e estruturado, cuja função primordial é a apreensão e o controle da realidade, permitindo sua compreensão e interpretação ${ }^{13}$. Nesse sentido, entende-se que a apreensão da realidade do trânsito em Florianópolis pelos membros da RVT poderá subsidiar as diversas instâncias governamentais, não governamentais e a sociedade civil para as mudanças e melhorias necessárias.

Este estudo teve como objetivo compreender o significado de vida no trânsito na perspectiva de membros da Rede Vida no Trânsito.

\section{MÉTODO}

\section{Tipo de estudo}

Pesquisa descritiva exploratória, qualitativa, baseada no referencial da Teoria das Representações Sociais (TRS) ${ }^{13}$.

\section{Local do estudo}

O cenário do estudo foi a Rede Vida no Trânsito (RVT), em Florianópolis, Santa Catarina.

\section{Participantes do estudo}

A seleção dos participantes foi intencional e seguiu como critérios de inclusão: ser membro da Rede; ter idade mínima de 18 anos; e, participar de atividades da RVT por no mínimo seis meses, período considerado suficiente para expressar a vivência do significado de vida no trânsito. Excluiram-se os membros da Rede em licença saúde, férias ou atuando em outro município durante a coleta de dados. A atuação profissional em outro município foi considerada um critério de exclusão em função da distância geográfica e a limitação de deslocamento dos pesquisadores a outras localidades. O contato dos participantes foi fornecido pela Secretaria Executiva da RVT. Ao final, com base no critério da saturação dos dados, a amostra do estudo foi composta por 30 participantes.

\section{Coleta de dados}

A coleta de dados, realizada de junho a agosto de 2016, por meio de entrevista individual semiestruturada, ocorreu em ambiente privativo das instituições que participam da RVT, após agendamento. O contato inicial para convidar os participantes do estudo se deu de modo presencial durante as reuniões da RVT. Quando isso não foi possivel, o contato foi efetivado por via telefônica. No primeiro contato, o objetivo da pesquisa era esclarecido e a entrevista era agendada conforme disponibilidade do participante.

Participaram do estudo representantes de 14 instituições, sendo três da área da saúde (13 entrevistados), seis 
instituições relacionadas ao trânsito (10 entrevistados) e cinco instituições do setor de segurança pública (sete entrevistados). As entrevistas tiveram tempo de duração de 10 a 32 minutos, foram gravadas e transcritas na íntegra por uma das pesquisadoras. As entrevistas foram guiadas pela pergunta disparadora: O que significa vida no trânsito para você?

\section{Procedimentos de análise e tratamento dos dados}

Para a organização e análise dos dados, utilizou-se - Software Qualiquantisoft do Discurso do Sujeito Coletivo (DSC), versão 1.3c. A técnica de análise de dados do DSC propõe quatro figuras metodológicas: Expressões-Chave (ECHs) - trechos ou transcrições literais do discurso que representam a essência do conteúdo da questão em análise; Ideia Central (IC) - expressão que revela e descreve o sentido de cada um dos discursos; Ancoragem (AC) - manifestação linguística explícita de uma dada teoria, ideologia ou crença que o autor do discurso professa e que está sendo usada pelo enunciador para enquadrar uma situação específica; e, Discurso do Sujeito Coletivo (DSC) propriamente dito - reunião das ECHs presentes nos depoimentos, que têm IC ou AC de significado semelhante ou complementar; escrito na primeira pessoa do singular, representa o pensamento de uma coletividade ${ }^{13-14}$

Desse modo, o primeiro passo na organização dos dados no Software foi o cadastramento da pesquisa, da pergunta e dos participantes. Na sequência, transferiu- se o conteúdo das respostas de cada questão por participante, conforme entrevistas transcritas no Microsoft Word $^{\circledR}$. O passo seguinte consistiu em identificar, em cada resposta, as ECHs e, posteriormente, identificar e nomear as ICs a partir daquelas. Em sequida, foram agrupadas e denominadas as ICs e AC com sentido equivalente ou complementar. O último passo foi à construção do DSC a partir das ECHs com a mesma IC ou AC. O Software possibilitou ainda identificar o quantitativo de agentes sociais (participantes do estudo) que aderiram cada uma das ICs e AC.

\section{Aspectos éticos}

A pesquisa foi aprovada pelo Comitê de Ética em Pesquisa da Universidade Federal de Santa Catarina, sob o parecern 1.513.132 de 2016, CAAE: 54782616.0.0000.0121. Foram cumpridas as normas de pesquisa com seres humanos no Brasil, em consonância com a Resolução n. 466/2012 do Conselho Nacional de Saúde. Todos os participantes assinaram o Termo de Consentimento Livre e Esclarecido (TCLE). Para preservar o anonimato dos par- ticipantes, utilizou-se a letra E (Entrevistado) seguida do número correspondente à sequência das entrevistas (El, $E 2, E 3 \ldots)$

\section{RESULTADOS}

Participaram do estudo 30 membros da RVT, sendo metade do sexo feminino. A faixa etária variou de 25 e 63 anos, todos com formação de ensino superior nas áreas de Medicina, Ciências Sociais, Odontologia, Economia, Enfermagem, Gestão Ambiental, Naturologia, Gestão de Negócios, Direito, Pedagogia, Educação Física, Sociologia, Jornalismo, História, Engenharia de Produção Civil ou Mecânica. Quanto à maior titulação dos participantes, 12 possuíam especialização, 10 mestrado e dois doutorado.

O tempo de atuação na RVT variou de seis meses a dois anos, período correspondente à criação da Rede. Todos os integrantes participam da RVT de modo espontâneo ou por indicação do seu trabalho. A participação na Rede ocorre nas reuniões mensais ampliadas, nos Grupos de Trabalho, no Grupo de Informação ou na Secretaria Executiva. Há os que se envolvem concomitantemente em mais de uma dessas atividades, conforme disponibilidade pessoal e/ou do local de trabalho.

Da análise dos depoimentos, emergiram uma AC e uma IC com seus respectivos DSC sobre o significado de vida no trânsito para os membros da RVT. Embora tenham participado do estudo 30 membros da RVT, oito tiveram no seu discurso tanto AC como IC, o que justifica o total de 38 envolvidos nas duas figuras metodológicas (AC e IC) (Tabela 1).

Tabela 1 - Ancoragem e Ideia Central referente ao significado de vida no trânsito para os membros da Rede Vida no Trânsito- Florianópolis, SC, Brasil, 2016.

\begin{tabular}{l|l|l|}
\hline \multirow{2}{*}{ Ancoragem (AC) e Ideia Central (IC) } & \multicolumn{2}{|l|}{ Participantes } \\
\cline { 2 - 3 } & $\mathrm{n}$ & $\%$ \\
\hline AC: Promoção da vida no trânsito & 27 & 71,1 \\
\hline $\begin{array}{l}\text { IC: Preservação da vida pela redução } \\
\text { dos acidentes }\end{array}$ & 11 & 28,9 \\
\begin{tabular}{l} 
Total \\
\hline
\end{tabular} & 38 & 100,0 \\
\hline
\end{tabular}

fonte: dados da pesquisa

O primeiro discurso (DSCl), que se refere à $A C$, teve maior representatividade. Neste, a Promoção da vida no trânsito se traduz em múltiplas perspectivas capazes de 
produzir mudanças na busca por condições ideais de vida no trânsito para todos e com a participação coletiva. São elementos promotores da vida no trânsito: educação; respeito; tolerância; investimento; segurança, dentre outros.

\section{AC - Promoção da vida no trânsito}

DSCl - Vida no trânsito significa você ter, acima de tudo, uma cidade que permita às pessoas se deslocarem para seu trabalho, seu lazer, de qualquer forma, usarem a rua como parte das suas vidas e escolherem como querem se deslocar. Tem muito a ver com a paz no trânsito, é o direito à vida, é essa questão bem social de direito de andar onde você quer, de forma tranquila e passiva. É saber que o local por onde ando vai ter uma infraestrutura adequada, de que não vai haver nenhum risco para a vida em decorrência do trânsito. Também é uma questão de segurança porque às vezes você pode ser vitima de um assalto, de um sequestro, por falta de segurança no trânsito. Significa desconstruir uma cultura de violência e trazer esse conceito de saúde para o trânsito, de que a gente precisa se deslocar e isso faz parte da nossa vida. O deslocamento não pode trazer outra coisa que não seja benefício para a nossa vida, que sempre a prioridade é a pessoa, é a vida humana, que o automóvel é apenas uma ferramenta. É ter harmonia no trânsito, boa convivência, melhores condições de estar nesse espaço compartilhado de uma forma mais sustentável, mais solidária e com foco na saúde. Significa tentar humanizar a cidade e que as pessoas tenham menos pressa, mais paciência. É a gente conseguir conviver com todos os parceiros que utilizam o trânsito para se locomover. Significa educação, respeito, investimento e tolerância. É retomar esse significado de relacionamento, entender que a gente tem vida e não disputa, é ressignificar esse relacionamento no trânsito, repensar o que estou fazendo no trânsito. Ser consciente, bom condutor, conhecer as regras de trânsito, andar dentro da legalidade (E1, E2, E3, E5, E6, E7, E8, E9, E10, El1, E12, E13, El4, El6, El7, E18, E19, E20, E21, E22, E23, E24, E25, E26, E28, E29, E30).
O segundo discurso (DSC2), relacionado à IC, retrata que, para 11 participantes do estudo, o significado de vida no trânsito está relacionado à preservação da vida pela redução dos acidentes que culminam em óbitos, evidenciando um problema a ser resolvido.

\section{IC - Preservação da vida pela redução dos acidentes DSC2 - O trânsito não pode matar porque ele} tira quantidade de vida e tem que ser exatamente o inverso do que temos hoje, diante dos óbitos ocorridos no trânsito (...) estamos perdendo vidas todos os dias, o que não pode acontecer (...) vida no trânsito significa a diminuição de óbitos no trânsito e poder ter um transporte com segurança, com preservação da vida, sem se acidentar, poder se locomover para qualquer lugar e ter a liberdade de ir e vir sem correr risco. Não só ficar contabilizando óbitos, e sim, buscar formas de poder viver realmente com o trânsito. Significa ainda um problema que a gente tem para resolver, é uma preocupação. Então, vida no trânsito é a gente euitar mortes (E1, E2, E3, E4, E6, E8, E9, Ell, E15, E23, E27).

\section{DISCUSSÃO}

Ambos os discursos revelam que os membros da RVT têm uma representação social positiva acerca do significado de vida no trânsito, pois se ancora na promoção ou preservação da vida nesse cenário, o que é fundamental para o alcance dos objetivos da RVT. Diferentemente, a literatura ${ }^{15-16}$ aponta que, de modo geral entre os profissionais da saúde e condutores de motocicleta, as concepções de trânsito estão ligadas aos desastres, congestionamentos, estresse, entre outros agravantes à vida.

As representações sociais estão relacionadas às expectativas e à visão de mundo de um determinado grupo de pessoas e permitem desvelar os significados elaborados e compartilhados nas interações sociais em um mundo concreto e particular ${ }^{13-14}$, o que pode justificar diferentes representações sobre a vida no trânsito. Nesse sentido, os participantes da pesquisa, por fazerem parte da RVT, compartilham experiências e conhecimentos e aderem aos objetivos e missão da Rede, construindo representações sociais próprias deste grupo e favoráveis à vida. Assim, constata-se coerência entre significados expressos pelos participantes e os objetivos da RVT. 
No tocante à promoção da vida no trânsito (AC), evidenciada no DSC 1, esta se traduz em um grande desafio, haja vista as circunstâncias de insegurança presentes no trânsito, a necessidade de se desconstruir a cultura de violência, de ressignificar o relacionamento das pessoas nesse cenário, dentre outros

No universo de ressignificação do trânsito, entende- se a participação e o controle social como elementos fundamentais. Assim, quando os participantes destacam a importância da harmonia no trânsito, boa convivência e uma postura solidária no trânsito fica implícito nos discursos que é essencial o envolvimento da comunidade na promoção da vida no trânsito em relação à tomada de consciência de si, do outro e do meio ambiente em que se vive, tendo a RVT a sua parcela de contribuição nesse sentido. Pela participação e pelo controle social, os indivíduos e as comunidades podem ampliar suas possibilidades de atuação sobre os fatores que afetam sua saúde e qualidade de vida ${ }^{17}$, a exemplo das condições desfavoráveis do trânsito.

Em consonância com a participação e o controle social para promover a vida no trânsito, ressalta- se a paz no trânsito, que movimenta a vida a favor de melhorias individuais e coletivas, buscando beneficiar a todos. O desejo de construir uma cultura de paz no trânsito, revelada no primeiro discurso, perpassa a modificação de crenças, valores, comportamentos, interações e relações entre as pessoas. Implica, ainda, em criar objetivos e estratégias, transformar estruturas ineficientes e abandonar zonas de comodismo ${ }^{18-19}$ que refletem 0 individualismo no trânsito, expresso pela culpabilização do outro e banalização de diferentes problemas que tornam esse espaço coletivo violento e inseguro.

Nessa lógica, a segurança no trânsito necessita de um processo educativo com foco no desenvolvimento de pessoas, para que estas compreendam suas ações e revejam sua participação nesse cenário. Isso é possivel a partir do desenvolvimento de funções sociais, o que depende de uma maior consciência individual e do incentivo à participação das pessoas no espaço público ${ }^{20}$, aspectos que constituem um desafio para a RVT.

Estudo aponta a humanização do trânsito como uma aliada na busca da resolutividade dos problemas por ele produzidos $^{16}$. Essa humanização, que no discurso dos membros da RVT (DSCl) está relacionada ao respeito pelas pessoas, à boa convivência e à tolerância no trânsito, pode ser entendida como um requisito à garantia do direito de ir e vir das pessoas, de se deslocar com se- gurança e harmonia em um ambiente mais agradável e sustentável.

Contudo, a mobilização da população em torno de posturas seguras e solidárias no trânsito, mediante ações que coíbam a vitimização das pessoas no exercício do direito elementar de ir e vir, é um desafio. Os veículos automotores representam posição social mais elevada e poder, incluindo percepções de prestígio, liberdade e prazer na sociedade contemporânea ${ }^{21-22}$

Nesse sentido, destaca-se a relevância de mobilização da "cultura do automóvel", como mencionado pelos participantes. Para tanto, é necessário repensar as adaptações realizadas nas cidades, as quais violam a natureza para favorecer o uso dos automotores, contribuindo para a poluição do meio ambiente e danos à qualidade de vida das pessoas, que têm os espaços coletivos, como praças e áreas de lazer, cedidos à abertura de novas vias ${ }^{16,21}$, aspectos que desfavorecem a criação e manutenção de ambientes seguros e saudáveis de vida nas cidades.

Assim, uma abordagem integrada no planejamento e desenho de áreas urbanas é indispensável no contexto atual da urbanização, das imposições relacionadas à escassez de recursos ambientais e da promoção da inclusão social, como parte dos esforços globais para se atingir padrões de vida e cuidados à saúde adequados para o alcance do desenvolvimento sustentável ${ }^{23-24}$. Acredita-se que a RVT poderá contribuir nesse sentido, tendo em vista a sua constituição, organização e dinâmica de trabalho, caracterizada por um grupo de profissionais de diferentes áreas do conhecimento, os quais atuam em ações distintas, voltadas à vida no trânsito.

Dentre os profissionais que constituem a RVT, destacam-se os enfermeiros, médicos e odontólogos, pois o setor saúde assume progressivamente um papel protagonista em iniciativas tradicionalmente restritas aos setores de segurança pública, engenharias e direito. Além disso, ressalta-se a ênfase na abordagem intersetorial do problema da segurança no trânsito e as contribuições com os preceitos mais modernos de epidemiologia e a visão de promoção da saúde, primando, nesta, antes pela integridade e qualidade de vida ${ }^{25-26}$, também apontadas pelos participantes em ambos os discursos desta pesquisa.

No que se refere à preservação da vida pela redução dos acidentes (IC), os participantes revelaram no DSC 2 uma realidade que não é aceita por eles - a dos acidentes que culminam em óbitos, porém a que se obrigam a conviver, o que gera insatisfação profissional e pessoal. Julga-se que essa representação se fundamenta nas 
estatísticas produzidas pela própria Rede, mas também naquelas divulgadas cotidianamente nos mais diversos veículos de comunicação, bem como em publicações científicas sobre a temática que retratam a mortalidade por acidentes de trânsito no Brasil ${ }^{8,21,27}$ e no mundo 9-12,28. Assim, as representações dos membros da RVT são concebidas como uma rede de conceitos e imagens interativas, que evoluem continuamente conforme o tempo e o espaço, diretamente proporcional à complexidade e velocidade das comunicações ${ }^{16}$.

A proximidade com as informações negativas acerca dos acidentes, geradas na Rede, e com as ações desenvolvidas na mesma, "alimenta" nos participantes do estudo o desejo de mudança e de preservar a vida no trânsito, identificando neles a função de orientação atribuída às representações sociais, as quais são responsáveis pela elaboração de condutas, comportamentos e práticas. Nesse sentido, a representação funciona como um sistema de pré-modificação da realidade, por determinar um conjunto de antecipações e expectativas sobre a mesma ${ }^{16}$.

Os participantes significam a vida no trânsito com a prevenção dos acidentes e consequentes mortes, um problema a ser resolvido. Embora as taxas de mortalidade no trânsito reforcem esta representação, os resultados de uma avaliação do Projeto Vida no Trânsito, desenvolvida no país, mostraram uma redução no número de mortes por acidentes em três das cinco capitais investigadas. Destacou-se no desempenho positivo do Projeto a intensificação das intervenções integradas e intersetoriais, decorrentes da parceria entre os setores do Trânsito, da Segurança Pública e da Saúde ${ }^{6}$, o que pode estimular a atuação dos participantes como membros da RVT.

Comparativamente, a avaliação do 'Global Road Safety Program' na Turquia revelou que o Programa contribuiu para algumas melhorias no trânsito, todavia, é difícil concluir que o mesmo teve algum impacto quantitativo nos acidentes e taxas de mortalidade, nas duas cidades onde o estudo foi desenvolvido, sendo uma delas a capital do país ${ }^{29}$. A avaliação do Programa também foi realizada em duas regiões da Rússia e evidenciou diminuição no número de mortes no trânsito em uma delas ${ }^{30}$.

Desse modo, ao passo em que os resultados dos esforços globais de segurança no trânsito ainda são incipientes, já é possível a identificação de avanços para o alcance da meta da Década de Ações para a Segurança no Trânsito 2011 - 2020. Além disso, essas evidências podem motivar outras iniciativas capazes de produzir impacto positivo à preservação e promoção da vida no trânsito pela garantia de direitos como, por exemplo, segurança.

\section{Limitações do Estudo}

O número de participantes e a pouca representatividade da sociedade civil no estudo, que ocorreu pelo fato da mesma ainda não ser parte atuante na RVT, podem ter limitado a interpretação dos resultados sob a perspectiva da coletividade e de compartilhamento de opiniões, conforme preconiza o referencial teórico da representação social. Porém, teve-se o cuidado de convidar todos os membros atuantes na Rede durante o período de coleta de dados, respeitados os critérios de inclusão do estudo, sendo contemplados na sua totalidade.

\section{Contribuições para a Prática}

O estudo confere visibilidade à participação do enfermeiro na "Rede Vida no Trânsito", que ainda pode ser desconhecida para os profissionais da área. Salienta-se que ao participar da Rede o enfermeiro pode contribuir com o desenvolvimento de estratégias voltadas para diferentes públicos com foco na preservação e promoção da vida no trânsito.

\section{CONCLUSÕES}

A representação dos participantes no que se refere à vida no trânsito está voltada para a promoção da vida neste cenário, relacionada às condições ideais de trânsito e mobilidade com segurança. Para os participantes, vida no trânsito também significa a preservação da vida pela redução dos acidentes, mediante mudanças na infraestrutura, adoção de políticas públicas legítimas e sustentáveis, bem como compreensão e participação de toda a sociedade, que deve buscar paz, respeito e educação no trânsito. Desse modo, a realidade cotidiana das pessoas nesse cenário sinaliza a necessidade de melhorias a fim de garantir vida e com qualidade.

Recomendam-se outros estudos que abordem a vida no trânsito e não somente os agravos ocorridos neste ambiente. Estatísticas também são necessárias, mas devem ser principalmente instrumentos para gerar mudanças, conscientizar e sensibilizar toda a sociedade que deve ser ativa na promoção diária de vida no trânsito. Muito mais do que indicadores e dados, consideram-se, aqui, vidas diariamente perdidas e condições insustentáveis que prejudicam a sociedade e isso precisa mudar. 


\section{REFERÊNCIAS}

1. Rede Vida no Trânsito. Boletim da Rede Vida no Trânsito [Internet]. Florianópolis; 2016 [cited 2017 Aug 25]. Available from: https://redevidanotransito.files.wordpress. com/2017/08/boletim-rvt-desastres-setl6.pdf

2. Mascarenhas MDM, Souto RMCV, Malta DC, Silva MMA Lima CM. Montenegro MMS. Characteristics of motorcyclists involved in road traffic accidents attended at public urgent and emergency services. Cienc Saude Colet [Internet]. 2016 [cited 2020 Oct 11]: 21(12):3661-3671. Available from: https://www.scielosp.org/pdf/csc/2016.v2ln12/36613671/en

3. World Health Organization (WHO). Department for Management of Noncommunicable Diseases, Disability, Violence and Injury Prevention. Road safety mass media campaigns: a toolkit [Internet]. Geneva; 2016. [cited 2016 Mar 7] Available from: http://apps.who.int/iris/bitstream/10665/2 54281/1/9789241511797-eng.pdf?ua=1

4. Ministério da Saúde (BR). Guia Vida no Trânsito. Brasilia: Universidade Federal de Goiás [Internet]. 2015 [cited 2016 Nov 13]. Available from: http://pesquisa.bvsalud.org/bvsms/ resource/pt/mis-38888

5. Morais Neto OL, Silva MMA. Lima CM, Malta DC, Silva Junior JB. Life in Traffic Project: evaluation of the implementation in five Brazilian state capitals, 2011-2012. Epidemio Serv Saúde [Internet]. 2013 [cited 2017 Jan 1]: 22(3):373-82. Available from: http://scielo.iec.pa.gov.br/pdf/ess/v22n3/ v22n3a02.pdf

6. Santos GM, Nery AA, Constâncio TOS, Oliveira JS, Carmo EA, Silva VAC, et al. Atendimentos do componente móvel da rede de atenção às urgências e emergências. Rev Cuid [Internet]. 2019 [cited 2020 Oct 11]; 10(3):e779. Available from: https://revistacuidarte.udes.edu.co/index.php/ cuidarte/article/view/779/1353

7. Aguilera SLVU, Sripad P, Lunnen JC, Moyses ST, Chandran A, Moysés SJ. Alcohol consumption among drivers in Curitiba, Brazil. Traffic Inj Prev [Internet]. 2015 [cited 2020 Oct 11]: 16(3):219-24. Doi: 10.1080/15389588.2014.935939

8. Andrade SSCA, Mello-Jorge MHP. Mortality and potential years of life lost by road traffic injuries in Brazil, 2013. Rev Saude Publica [Internet]. 2016 [cited 2017 Jul 12]; 50:59.
Available from: http://www.scielo.br/pdf/rsp/v50/00348910-rsp-S1518-87872016050006465.pdf

9. Otzen T, Sanhueza A, Manterola C. Hetz M. Melnik T. Transport accident mortality in Chile: trends from 2000 to 2012. Cien Saude Colet [internet]. 2016 [cited 2017 Jul 24]; 21(12):3711-18. Available from: http://www.scielo.br/pdf/ csc/v2ln12/1413-8123-csc-21-12-3711.pdf

10. Gopaul CD, Singh-Gopaul A, Sutherland JM, Rostant L, Ebi KL. Chadee DD. The epidemiology of fatal road traffic collisions in Trinidad and Tobago. West Indies (2000-2011). Glob Health Action [Internet]. 2016 [cited $2017 \mathrm{Jul}$ 28]; 9:32518. Available from: https://www. ncbi.nlm.nih.gov/pmc/articles/PMC5105321/pdf/GHA-932518.pdf

11. Sadeghi-Bazargani H, Ayubi E, Azami-Aghdash S, Abedi L. Zemestani A, Amanati L, et al. Epidemiological patterns of road traffic crashes during the last two decades in Iran: a review of the literature from 1996 to 2014. Arch Trauma Res [Internet]. 2016 [cited 2020 Oct 11]; 5(3):e32985. Available from: http://eprints.kaums.ac.ir/1175/1/atr-05-03$32985 \% 282 \% 29$.pdf

12. Cardona AMS, Arango DC, Fernández DYB, Martínez AA. Mortalidad por accidente de tránsito en el adulto mayor en Colombia. Rev Saude Publica [Internet]. 2017 [cited 2017 Jul 22]: 51:21. Available from: http://www.scielo.br/pdf/rsp/v51/ es_0034-8910-rsp-S1518-87872017051006405.pdf

13. Lefèvre F, Lefèvre AMC. Pesquisa de representação social: um enfoque qualiquantitativo: a metodologia do Discurso do Sujeito Coletivo. 2 ed. Brasilia: Liber Livro Editora; 2012. $224 \mathrm{p}$.

14. Morera JAC. Social representations and social cognition: contributions to nursing and health research. Texto Contexto Enferm [Internet]. 2017 [cited 2020 Oct 11]: 26(4 ):e1500017. Available from: https://www.scielo.br/pdf/tce/ v26n4/en_0104-0707-tce-26-04-el500017.pdf

15. Souza HNF, Drumond EF, Malta DC, Costa TAH, Freitas MIF. Perspective of motorcyclists accidented about risk and transit accidents. Rev Min Enferm [Internet] 2018 [cited 2020 Oct 11]; 22:e-1088. Available from: https://cdn.publisher.gnl.link/reme.org.br/pdf/en_el088.pdf 
16. Lira L, Gomes ARF, Farias MSJA, Rocha MNT, Rodrigues MS, Taveira MGMM. Knowledge of traffic humanization by health professionals. Revista Portal: Saúde e Sociedade [Internet]. 2016 [cited 2017 Mar 13]; 1(3):205-16. Available from: http://www.seer.ufal.br/index.php/nuspfamed/article/view/2683/2157

17. World Health Organization (WHO). The Ottawa charter for health promotion [Internet]. Ottawa; 1986 [cited 2016 Jul 10]. Available from: http://www.who.int/healthpromotion/conferences/previous/ottawa/en/

18. Moreira LS, Branco AMCUA. Processo de socialização e promoção da cultura de paz na perspectiva de policiais militares. Estud Psicol (Campinas) [Internet]. 2016 [cited 2020 Apr 25]: 33(3):553-63. Available from: http://www.scielo.br/pdf/estpsi/v33n3/0103-166X-estpsi-33-03-00553. pdf

19. De Lira FB, Ulle CMS, De Mattos M. Acidentes motociclisticos e ações educativas no trânsito em municipio do estado de Mato Grosso. Enferm Foco [Internet]. 2019 [cited 2020 Apr 25]; 10(3):141-146. Available from: http:// revista.cofen.gov.br/index.php/enfermagem/article/ view/2013/567

20. Barbosa BCV. Empreendendo o I Núcleo interdisciplinar universitário de trânsito de Pernambuco - Niut, como proposta para um trânsito sustentável. Interfaces - Revista de Extensão da UFMG [Internet]. 2014 [cited 2020 Apr 25]; 2(3):119-32. Available from: https://www.ufmg.br/proex/revistainterfaces/index.php/IREXT/article/view/38/pdf

21. Van Belleghem G, Van Deynse H, Devos S, Huysmans E, Hubloue I, Lauwaert D, et al. Health care utilization after hospitalization following a road traffic accident. Disabil Rehabil [Internet]. 2019 [cited 2020 Oct 11]; 42(11):1599-1606. Doi: $10.1080 / 09638288.2018 .1531152$

22. Paixão LMMM, Gontijo ED, Mingoti SA, Costa DAS, Friche AAL, Caiaffa WT. Urban road traffic deaths: data linkage and identification of high-risk population sub-groups. Cad Saúde Pública [Internet]. 2015 [cited 2017 May 2]; 31(1 Suppl):92-106. Available from: http://www.scielo.br/pdf/csp/ v31sl/0102-311X-csp-31-sl-0092.pdf

23. Marins KRCC. Análise comparativa multicriterial de estratégias em sustentabilidade urbana aplicada aos bairros de Cidade Pedra Branca (Palhoça, SC) e Vauban (Frei- burg. Alemanha). Ambiente Construido [Internet]. 2017 [cited 2020 Apr 25]: 17(1):393-408. Available from: http://www.scielo.br/pdf/ac/v17nl/1678-8621-ac-17-01-0393.pdf

24. Macedo VLM, Vieira LF, Neves RS, Leandro SS. Avaliação da estratégia saúde da familia em São Sebastião - Distrito Federal. Enferm Foco [Internet]. 2019 [cited 2020 Apr 25]; 10(2):15-21. Available from: http://revista.cofen.gov.br/index. php/enfermagem/article/view/2330/540

25. Pavarino Filho RV. The Moscow and Brasilia Declarations on road safety - a parallel between two moments in health. Cien Saude Colet [Internet]. 2016 [cited 2017 Jul 24]; 21(12):3649-60. Available from: http://www.scielo.br/pdf/ csc/v2ln12/en_1413-8123-csc-21-12-3649.pdf

26. Moll MF, Boff NN, Silva PS, Siqueira TV, Ventura CAA O enfermeiro na saúde da família e a promoção de saúde e prevenção de doenças. Enferm Foco [Internet]. 2019 [cited 2020 Apr 25]; 10(3):134-140. Available from: http://revista. cofen.gov.br/index.php/enfermagem/article/view/2001/570

27. Mandacaru PMP, Andrade AL, Rocha MS, Aguiar FP, Nogueira MSM, Girodo AM, et al. Qualifying information on deaths and serious injuries caused by road traffic in five Brazilian capitals using record linkage. Accid Anal Prev [Internet]. 2017 [cited 2017 Jul 28]; 106:392-8. Available from: https://doi.org/10.1016/j.aap.2017.06.018

28. Hasanzadeh J, Moradinazar M, Najafi F, Ahmadijouybary T. Trends of mortality of road traffic accidents in Fars Province, Southern Iran, 2004-2010. Iranian J Publ Health [Internet]. 2014 [cited 2017 Jul 24]; 43(9):1259-65. Available from: https://www.ncbi.nlm.nih.gov/pmc/articles/PMC4500428/ pdf/IJPH-43-1259.pdf

29. Gupta S, Hoe C, €Ozkan T, Lajunen TJ, Vursavas F, Sener S, et al. Evaluation of a five-year Bloomberg Global Road Safety Program in Turkey. Public Health [Internet]. 2017 [cited 2017 Jul 26]; 144(Suppl):S45-S56. Available from: http:// www.publichealthjrnl.com/article/S0033-3506(17)30013-6/ pdf

30. Gupta S, Paichadze N, Gritsenko E, Klyavin V, Yurasova E, Hyder AA. Evaluation of the five-year Bloomberg Philanthropies Global Road Safety Program in the Russian Federation. Public Health [Internet]. 2017 [cited 2017 Jul 26]; 144(Suppl):S5-S14. Available from: http://www.publichealthjrnl.com/article/S0033-3506(16)30451-6/pdf 